\title{
Pharmacodynamic comparison of different antimicrobial regimens against Staphylococcus aureus bloodstream infections with elevated vancomycin minimum inhibitory concentration
}

Thaina Miranda da Costa ${ }^{1 *+}$, Gabriel Trova Cuba ${ }^{2^{*+}}$ (D) Priscylla Guimarães Migueres Morgado ${ }^{1}$, David P. Nicolau ${ }^{3}$, Simone Aranha Nouér ${ }^{4}$, Kátia Regina Netto dos Santos ${ }^{1}$ and Carlos Roberto Veiga Kiffer $^{2}$

\begin{abstract}
Background: Staphylococcus aureus is one of the major causes of bloodstream infections (BSI) worldwide, representing a major challenge for public health due to its resistance profile. Higher vancomycin minimum inhibitory concentrations (MIC) in S. aureus are associated with treatment failure and defining optimal empiric options for BSIs in settings where these isolates are prevalent is rather challenging. In silico pharmacodynamic models based on stochastic simulations (Monte Carlo) are important tools to estimate best antimicrobial regimens in different scenarios. We aimed to compare the pharmacodynamic profiles of different antimicrobials regimens for the treatment of S. aureus BSI in an environment with high vancomycin MIC.
\end{abstract}

Methods: Steady-state drug area under the curve ratio to MIC (AUC/MIC) or the percent time above MIC (fT > MIC) were modeled using a 5000-patient Monte Carlo simulation to achieve pharmacodynamic exposures against 110 consecutive S. aureus isolates associated with BSI.

Results: Cumulative fractions of response (CFRs) against all S. aureus isolates were $98 \%$ for ceftaroline; $79 \%$ and $92 \%$ for daptomycin $6 \mathrm{mg} / \mathrm{kg}$ q24h and for the high dose of $10 \mathrm{mg} / \mathrm{kg}$ q24h, respectively; $77 \%$ for linezolid $600 \mathrm{mg}$ q12h when MIC was read according to CLSI M100-S26 instructions, and 64\% when MIC was considered at the total growth inhibition; $65 \%$ and $86 \%$ for teicoplanin, three loading doses of $400 \mathrm{mg} \mathrm{q} 12 \mathrm{~h}$ followed by $400 \mathrm{mg}$ q24 $\mathrm{h}$ and for teicoplanin $400 \mathrm{mg}$ $\mathrm{q} 12 \mathrm{~h}$, respectively; $61 \%$ and $76 \%$ for vancomycin $1000 \mathrm{mg} \mathrm{q12} \mathrm{h}$ and $\mathrm{q} 8 \mathrm{~h}$, respectively.

(Continued on next page)

\footnotetext{
*Correspondence: thainamc@uol.com.br; gbtrova@gmail.com

†Thaina Miranda da Costa and Gabriel Trova Cuba contributed equally to this work.

'Laboratório de Infecção Hospitalar, Departamento de Microbiologia Médica, Instituto de Microbiologia Paulo de Góes, Universidade Federal do Rio de Janeiro, Av. Carlos Chagas Filho, 373 - bloco I, Sala 12-010, Cidade Universitária Rio de Janeiro, Rio de Janeiro, Brazil

${ }^{2}$ Laboratório Especial de Microbiologia Clínica, Disciplina de Infectologia, Escola Paulista de Medicina, Universidade Federal de São Paulo (UNIFESP), Rua Leandro Dupret, São Paulo, SP 188, Brazil

Full list of author information is available at the end of the article
}

C The Author(s). 2020 Open Access This article is distributed under the terms of the Creative Commons Attribution 4.0 International License (http://creativecommons.org/licenses/by/4.0/) which permits unrestricted use, distribution, and reproduction in any medium, provided you give appropriate credit to the original author(s) and the source, provide a link to the Creative Commons license, and indicate if changes were made. The Creative Commons Public Domain Dedication waiver (http://creativecommons.org/publicdomain/zero/1.0/) applies to the data made available in this article, unless otherwise stated. 


\begin{abstract}
(Continued from previous page)
Conclusions: Based on this model, ceftaroline and high-dose daptomycin regimens delivered best pharmacodynamic exposures against S. aureus BSIs. Teicoplanin higher dose regimen achieved the best CFR (86\%) among glycopeptides, although optimal threshold was not achieved, and vancomycin performance was critically affected by the $S$. aureus vancomycin MIC $\geq 2 \mathrm{mg} / \mathrm{L}$. Linezolid effectiveness (CFR of 73\%) is also affected by high prevalence of isolates with linezolid MIC $\geq 2 \mathrm{mg} / \mathrm{L}$. These data show the need to continually evaluate the pharmacodynamic profiles of antimicrobials for empiric treatment of these infections.
\end{abstract}

Keywords: Bloodstream infections, Staphylococcus aureus, Pharmacodynamic targets, Ceftaroline, Daptomycin, Vancomycin

\section{Background}

Bloodstream infections (BSI) are conditions of elevated incidence in nosocomial environments, particularly in critically ill patients. They have been associated with longer hospital stays, higher costs, and higher crude mortality rates [1]. Staphylococcus aureus is one of the main pathogens associated with BSI worldwide and in Brazil, and methicillinresistant S. aureus (MRSA) is associated with a significant elevated mortality risk $[1,2]$. Although $S$. aureus is a challenge for public health, vancomycin has been the cornerstone of treatment of patients with MRSA infections for more than fifty years $[3,4]$. However, increasing reports of reduced susceptibility to vancomycin are of great concern, especially since higher mortality rates in MRSA BSI have been associated with increased vancomycin MIC $(\geq 2 \mathrm{mg} / \mathrm{L}$ in some studies) $[5,6]$. While several anti-MRSA agents such as ceftaroline, daptomycin and linezolid have been used as alternatives to glycopeptides (vancomycin and teicoplanin), limited clinical and pharmacodynamic (PD) comparative data are available to assess their utility in MRSA BSI [7-9].

Monte Carlo simulation is a stochastic prediction tool, which is implemented by computer mathematical methods associating different variables, such as the pharmacokinetic (PK) profile of antimicrobials and the in vitro susceptibility data (i.e., MIC distribution), in order to estimate the antibiotics dosing regimens' probability of achieving targeted PD exposures [10]. The use of in silico PD models based on stochastic simulations is an important tool to explore optimal antimicrobial regimens in different populations or in specific settings $[11,12]$. These models allow exploration of different dosing regimens and targets in virtual scenarios, in order to explore best strategies to overcome challenging conditions [11], such as resistance emergence. Previous evaluations of different antimicrobial PD against $S$. aureus have already been published [13, 14].

The aim of the present study was to determine the probability of target attainment of different regimens of ceftaroline, daptomycin, linezolid, teicoplanin, and vancomycin using Monte Carlo simulation. The probability of microbiological success of these antimicrobials based on PK/PD simulations was assessed against $S$. aureus isolates from BSI from an university teaching hospital, where resistance to various antimicrobials and increasing MIC values has been previously observed [15].

\section{Methods}

\section{Microbiology and ethics statement}

This study was performed at the University Hospital Clementino Fraga Filho, a public tertiary teaching hospital in Rio de Janeiro, Brazil, with about 70,000 patients/day per year during the study period. It was approved by Human Research Ethics Committee of the University Hospital Clementino Fraga Filho (number 008/15).

A retrospective analysis was conducted evaluating all episodes of S. aureus BSI occurring in adults between February 2011 and December 2013, as defined by hospital control specialists as the first $S$. aureus isolate from a BSI episode and with subsequent initiation of anti-staphylococcal therapy. Only single and consecutive isolates were included in the present study (i.e. one $S$. aureus isolate from a single patient with first episode submitted to therapy).

All blood cultures were routinely processed using BacT/ALERT $^{\circ}$ (BioMerieux Inc., Durham, NC, USA) during the referred period. Bacterial identification was carried out by the automated VITEK 2 system (BioMerieux, Durham, NC, USA). Identification of bacteria was confirmed using Gram staining, catalase and coagulase production, and evaluation of $0.04 \mathrm{U}$ bacitracin resistance by disk-diffusion [16].

Cefoxitin disk (CECON, São Paulo, Brazil) diffusion test for evaluating oxacillin resistance was performed for all selected isolates, according to CLSI recommendations [17]. Determination of MICs was performed by broth microdilution, using fresh cation-adjusted Mueller-Hinton broth (CAMHB) for vancomycin, teicoplanin, linezolid, daptomycin (Sigma-Aldrich Chemical Company, St Louis, MO, USA) and ceftaroline (donated by AstraZeneca Pharmaceuticals, Schaumburg, IL, USA). CAMHB was supplemented with $50 \mu \mathrm{g} / \mathrm{mL}$ calcium for daptomycin assay. Linezolid MIC was determined considering growth inhibition of 100\% (linezolid-100) and also according to CLSI M100-S26 document (designated linezolid-80). The CLSI interpretative breakpoints were used for all antimicrobials [17]. The ATCC strains 25923 and 29213 were used as controls for 
the disk diffusion and MIC tests, respectively. The mecA gene detection was performed as previously described [18] for isolates resistant to cefoxitin by disk diffusion.

\section{Antibiotic regimens}

Steady-state exposure was assessed for the following antibiotic regimens by the methodology described below: daptomycin $6 \mathrm{mg} / \mathrm{kg}$ q24h; daptomycin $10 \mathrm{mg} / \mathrm{kg}$ q24h; linezolid $600 \mathrm{mg}$ q12h; teicoplanin three $400 \mathrm{mg}$ q12h as loading dose, followed by $400 \mathrm{mg}$ q $24 \mathrm{~h}$; teicoplanin 400 mg q12h; vancomycin $1000 \mathrm{mg}$ q8h; vancomycin 1000 mg q12h; ceftaroline $600 \mathrm{mg}$ q12h.

\section{Pharmacokinetic / pharmacodynamic (PK/PD) models}

Mean PK parameters and their distributions were extrapolated from published patient studies for each antibiotic. For studies to be considered, they had to be conducted in at least 10 actual patients (defined as a clinical study in the presence of an infection), to have described the assay used to determine drug concentrations and presented mean and standard deviation results for the total body clearance in liters per hour, volume of distribution of the central compartment and other pertinent PK parameters. Mean PK parameters and distribution were extrapolated from selected published studies for each antibiotic [19$22]$, and distribution curves were assumed in the PD model according to each parameter.

The PK/PD parameters (fAUC, total AUC or $f \mathrm{~T}>$ MIC) were chosen based on PD exposure-response relationship for each agent [22-26]. $\mathrm{AUC}_{0-24 \mathrm{~h}}$ was calculated by dividing Dose D4hours $/$ Clearance and then this value was divided by each MIC dilution between $0.625 \mathrm{mg} / \mathrm{L}$ to $16 \mathrm{mg} / \mathrm{L}$ to provide the total AUC/MIC (for linezolid and vancomycin) or fAUC/MIC (for daptomycin) calculation [13, 14]. Teicoplanin $\mathrm{AUC}_{0-24}$ was calculated using the trapezoidal rule and divided by each MIC dilution as previously described [13]. Each antimicrobial and their respective PK published studies and PD targets adopted are described in specific subsections (described in more detail below). Supplementary table summarizes the PK parameters derived from published studies, their respective references, and the PD targets chosen for each antimicrobial used in the Monte Carlo simulation.

\section{Daptomycin}

The PK parameters of daptomycin were derived from a study with 58 subjects treated for severe gram-positive infections [19]. Daptomycin PK model considered an 80 $\mathrm{kg}$ weight individual, with total body clearance of $0.8 \pm$ $0.14 \mathrm{~L} / \mathrm{h}$, protein binding of 90 to $93 \%$, linear and doseproportional PK over dose range studied $(6 \mathrm{mg} / \mathrm{kg} / \mathrm{dose}$ and $10 \mathrm{mg} / \mathrm{kg} /$ dose) [19, 27]. Daptomycin PD target of fAUC/MIC > 40 was chosen, previously associated with bacteriostasis in thigh murine infection model [23].

\section{Linezolid}

Linezolid PK data was obtained from a study with 318 adults with gram-positive infections (community-acquired pneumonia and skin and soft tissue infections) treated under the compassionate-use protocol [20]. The Linezolid PK model then assumed a total body clearance of $6.85 \pm 3.45 \mathrm{~L} / \mathrm{h}$ [20] and a one-compartment model $[13,28]$. Linezolid PD target was total AUC/MIC > 82.9, exposure required for a bacteriostatic response in neutropenic murine thigh infection model [24].

\section{Teicoplanin}

Teicoplanin PK were derived from a population study with 30 febrile and severely neutropenic patients. Teicoplanin PK then assumed a total body clearance of $1.15 \pm 0.56 \mathrm{~L} / \mathrm{h}$, volume of the central compartment $(6.56 \pm 4.01 \mathrm{~L}), \mathrm{k} 12$ $\left.(1.29 \pm 0.62 \mathrm{~h})^{-1}\right)$ and $\left.\mathrm{k} 21(0.18 \pm 0.08 \mathrm{~h})^{-1}\right)$, and a twocompartment model until steady state, to account for its long half-life [13, 21]. Teicoplanin PD target was a total AUC/ MIC $\geq 900$, exposure correlated with bacteriological response in patients with documented MRSA infection [25].

\section{Vancomycin}

Vancomycin PK data were derived from a populational study of patients receiving treatment for $S$. aureus lower respiratory tract infection [22]. Vancomycin total body clearance was estimated as a function of creatinine clearance $(\mathrm{CrCl}, \mathrm{mL} / \mathrm{min})$; drug clearance $(\mathrm{L} / \mathrm{h})=[(\mathrm{CrCl} \cdot 0.79)+15.4] \cdot 0.06[22]$. CrCl was assumed to follow a triangular distribution, simulated as a range between $50 \mathrm{~mL} / \mathrm{min}$ and $120 \mathrm{~mL} / \mathrm{min}$ [13]. Vancomycin PD target was total AUC/ MIC $\geq 350$, which was the exposure associated with clinical success for lower respiratory tract infections, approximately corresponding to a trough vancomycin concentration of $15-20 \mathrm{mg} / \mathrm{mL}$ [29].

\section{Ceftaroline}

Ceftaroline probability of target attainment (PTA) was obtained from literature $[26,30]$. The model was derived from a three-compartment model developed from plasma concentration from Phase 1, 2, 3 studies, the two latter in patients with complicated skin infection and communityacquired pneumonia [31]. Ceftaroline PD target used was $51 \% f \mathrm{~T}>\mathrm{MIC}$, which is an exposure associated with 2$\log _{10}$ CFU reduction from baseline for $S$. aureus on murine thigh and lung infection models [26].

\section{Monte Carlo simulation}

A 5000-patient Monte Carlo simulation (Crystal Ball 2000; Decisioneering Inc., Denver, CO, USA) was performed to calculate a population of total AUC/MIC (free or total) or $\mathrm{T}>\mathrm{MIC}$ exposures for each antibiotic regimen at each MIC dilution. Clearance, volume of the central compartment, k12 and k21 were each assumed to follow log-Gaussian distributions during simulations for teicoplanin. For the vancomycin 
simulation, creatinine clearance was assumed to follow a triangular distribution as previously described [13]. The number of simulated patients achieving the target PD exposure at each MIC was counted and reported as the PTA at that specific MIC (values in percentages). The cumulative fractions of response (CFR) was calculated as previously described for each drug [32], multiplying the PTA at each MIC by the percentage of isolates with that specific MIC. Final CFR results were obtained as the sum of each PTA per MIC and a CFR $\geq$ 90\% was considered optimal [14].

\section{Sensitivity analysis}

A sensitivity analysis was conducted to explore the robustness of the CFR against entire BSI S. aureus isolates. In order to perform the analysis, different PD targets were applied as a way of comparison with targets originally applied, as follows. For vancomycin sensitivity analysis, an alternative PD target of AUC/MIC > 400 was used, which was the exposure associated with superior clinical response in lower respiratory tract infections [22]. For daptomycin, PD targets of $f$ AUC/MIC $>12$ (the minimum value providing static effect with MRSA) and $>171$ (the minimum ratio which provided 99\% kill) were obtained from a thigh murine infection model [23]. For linezolid, the alternative PD targets of total AUC/ MICs > 51.85 (minimum breakpoint associated with clinical cure) and > 128 (median AUC/MIC associated to bacterial eradication in the blood of adult patients enrolled in the compassionate use program of linezolid) were also explored [33]. For ceftaroline, $f \mathrm{~T}>\mathrm{MIC}$ targets of 26 and $36 \%$ were also analyzed, which are targets associated to bacterial reduction endpoints of net bacterial stasis and $1-\log _{10}$ CFU reductions from baseline for $S$. aureus based on murine infection models, respectively [26]. Finally, teicoplanin trough value of $>13 \mathrm{mg} / \mathrm{L}$ and $>$ $20 \mathrm{mg} / \mathrm{L}$ were investigated, they are currently used in clinical practice $[34,35]$.

\section{Results}

A total of 110 single $S$. aureus isolates associate to one BSI episode were included in the analysis. It is relevant to note that $25(23 \%)$ isolates presented $\mathrm{MIC}=2 \mathrm{mg} / \mathrm{L}$ and $6(5 \%)$ presented $\mathrm{MIC}=4 \mathrm{mg} / \mathrm{L}$ to vancomycin, respectively. One VISA isolate was also ceftarolineintermediate (MIC of $2 \mathrm{mg} / \mathrm{L}$ ). Thirty-one (28\%) isolates were resistant to cefoxitin by disk diffusion and carried the mecA gene (MRSA).

Table 1 summarizes the MIC distributions of vancomycin, teicoplanin, linezolid, daptomycin and ceftaroline. Both linezolid readings were considered as part of the exploratory model for CFR analysis. It was observed that linezolid MICs ranged from 0.25 to $4 \mathrm{mg} / \mathrm{L}$ and from 0.25 to $2 \mathrm{mg} / \mathrm{L}$ for linezolid-100 and-80, respectively. The MIC results for linezolid-80 were one doubling- dilution lower than those read at $100 \%$ inhibition for 39 (35\%) isolates. Non-susceptibility to daptomycin was observed in 16 (14.5\%) isolates, which represented 35.5\% of the MRSA isolates.

Fig. 1 summarizes the MIC distributions and PTAs for ceftaroline, daptomycin, linezolid-100, linezolid-80, teicoplanin and vancomycin. Linezolid, vancomycin and all daptomycin regimens achieved $>90 \%$ target attainment up to MICs of $1 \mathrm{mg} / \mathrm{L}$. It was observed $>90 \%$ PTA up to MIC of 0.125 and $0.25 \mathrm{mg} / \mathrm{L}$ for teicoplanin three $400 \mathrm{mg}$ q12h followed by $400 \mathrm{mg}$ q24h and for teicoplanin $400 \mathrm{mg}$ q12h, respectively.

Table 2 summarizes the CFRs against the entire collection of BSI S. aureus isolates. Ceftaroline (98\%) and a higher daptomycin dose regimen $(10 \mathrm{mg} / \mathrm{kg})(92 \%)$ both achieved the CFR threshold defined as a limit for optimal therapy against the population tested. Teicoplanin $400 \mathrm{mg}$ q12h provided 86\% CFR, while daptomycin 6 $\mathrm{mg} / \mathrm{kg}$, vancomycin $1000 \mathrm{mg} \mathrm{q} 8 \mathrm{~h}$ and $1000 \mathrm{mg}$ q12h, and linezolid $600 \mathrm{mg}$ q12h all provided below 80\% CFRs.

Table 2 also shows the sensitivity analyses for the PD targets used against the entire BSI S. aureus isolates. Ceftaroline achieved the greatest CFR and remained above optimal threshold ( $\geq 90 \%$ ) despite different targets used. A very wide range of CFRs for daptomycin minimum bacteriostatic and minimum bactericidal targets (a CFR between 2 and 99\% and 15-100\% for $6 \mathrm{mg}$ / $\mathrm{kg}$ and $10 \mathrm{mg} / \mathrm{kg}$ regimens, respectively) were observed. Teicoplanin trough concentration values targets provided inferior CFR results when compared to the clinical derived PK target. Sensitivity analysis evidenced that optimal CFR for linezolid was not achieved even if the lowest PD was chosen (AUC/MIC of 51.85). As indicated in Table 2, CFR were similar between AUC/MIC $>350$ (73\%) and AUC/MIC > 400 (76\%) targets for vancomycin $1000 \mathrm{mg}$ q8h regimen; considering $1000 \mathrm{mg}$ $\mathrm{q} 12 \mathrm{~h}$ regimen, however, a large variation (40 and 62\%, respectively) was reported.

\section{Discussion}

Inappropriate antibiotic therapy is identified as an important predictor of mortality among patients with $S$. aureus bacteremia and higher vancomycin MIC values may be predictive of treatment failure $[6,36]$. Given the availability of different antimicrobials for the treatment of nosocomial S. aureus infections, define empirical options for BSI in settings where high-vancomycin MIC $S$. aureus isolates are prevalen needs further discussion. The present study analyzed 110 single and consecutive $S$. aureus isolates associated to unique BSI episodes, obtained during 2011 to 2013, from a complex hospital environment in Brazil. Our current S. aureus sample represents this scenario, since $28 \%$ of all presented vancomycin $\mathrm{MIC} \geq 2 \mathrm{mg} / \mathrm{L}$. In this environment, both 
Table 1 Minimum Inhibitory Concentrations distributions determined for 110 Staphylococcus aureus isolates from bloodstream infections

\begin{tabular}{|c|c|c|c|c|c|c|c|}
\hline \multirow[t]{3}{*}{ Antimicrobial } & \multicolumn{7}{|c|}{$\mathrm{N}^{\circ}(\%)$ of isolates } \\
\hline & \multicolumn{7}{|c|}{ MIC value in $\mathrm{mg} / \mathrm{L}$} \\
\hline & 0.0625 & 0.125 & 0.25 & 0.5 & 1 & 2 & 4 \\
\hline Ceftaroline & $2(2)$ & $51(46)$ & $33(30)$ & $11(10)$ & $12(11)$ & $1(1)$ & 0 \\
\hline Daptomycin & 0 & 0 & $3(3)$ & $26(23)$ & $65(59)$ & $12(11)$ & $4(4)$ \\
\hline Linezolid-100 & 0 & 0 & $1(1)$ & 0 & $15(14)$ & $83(75)$ & $11(10)$ \\
\hline Linezolid- $80^{\mathrm{a}}$ & 0 & 0 & $1(1)$ & $1(1)$ & $42(38)$ & $66(60)$ & 0 \\
\hline Teicoplanin & 0 & 0 & $71(64)$ & $33(30)$ & $5(5)$ & 0 & $1(1)$ \\
\hline Vancomycin & 0 & 0 & 0 & $4(4)$ & $75(68)$ & $25(23)$ & $6(5)$ \\
\hline
\end{tabular}

MIC Minimum Inhibitory Concentrations, ${ }^{a}:$ MIC Endpoint values for linezolid were read at the first well where the trailing begins without regard for pinpoint trailing, as CLSI M100-S26 instructions, being designated as linezolid-80; and at 100\% inhibition of growth, identified as linezolid-100

vancomycin regimens (1000 $\mathrm{mg} \mathrm{q} 12 \mathrm{~h}$ and $1000 \mathrm{mg} \mathrm{q} 8 \mathrm{~h})$ were unable to achieve the optimal defined threshold CFR (62 and 76\%, respectively), probably due to a high MIC prevalent environment. As confirmed by the sensitivity analysis, even higher vancomycin dose regimens would still attain suboptimal efficacy considering both PD (clinical cure and bacterial eradication) indexes.

Determining treatment strategies using other antistaphylococcal agents should be explored in order to provide alternative empiric treatment options in settings where elevated vancomycin MIC are prevalent [22, 37]. Based in our model, higher daptomycin dosing regimen $(10 \mathrm{mg} / \mathrm{kg}$ q24h) and currently FDA approved ceftaroline dosing regimen (600 $\mathrm{mg}$ q12h) performed an interesting therapeutic options from a PD standpoint. Ceftaroline is the only beta-lactam antibiotic commercially available in many countries (USA and others) with inherent activity against MRSA, however it is not currently approved for $S$. aureus BSI treatment [38]. On the other hand, daptomycin has label indication for the treatment of S. aureus BSI and right-side endocarditis [9].

Historically, daptomycin has been used as salvage therapy in patients failing vancomycin therapy, but its use has been increasingly common as initial empiric therapy [39]. Although daptomycin FDA approved dose regimen for of S. aureus BSI treatment is $6 \mathrm{mg} / \mathrm{kg}$ q24h, higher dose regimens would probably need to be used $(10 \mathrm{mg} /$ $\mathrm{kg}$ q24h or more) in order to overcome daptomycin non-susceptibility or in specific situations such as complicated or persistent MRSA bacteremia or profound infections [38]. Notably, there is an apparent correlation between daptomycin non-susceptibility and vancomycin intermediate resistance $[40,41]$.

As a limitation of the data, we must consider the sensitivity analysis for daptomycin. It illustrates the difficulties of translating in vitro bacteriostatic and bactericidal concepts into clinical practice [42]. In summary, bacteriostatic in vitro threshold used for daptomycin and observed in murine model studies would be only achieved with high- dose daptomycin regimens; thus, bactericidal targets would rarely be attained against isolates with similar MIC distributions. This also shows that the level of uncertainty in the current study is higher for daptomycin and further studies are needed to define relevant PD targets.

Ceftaroline is approved by the FDA for bacterial skin infections and community-acquired bacterial pneumonia, but there is increasing evidence of its use for treatment of patients with $S$. aureus BSI $[8,38,40]$, including treatment of serious MRSA infections and those caused by strains with reduced susceptibility to vancomycin and nonsusceptibility to daptomycin [43]. Although a $f T>$ MIC between 25 to $30 \%$ is reported as an appropriate target for complicated skin and skin structure infections [26], we have chosen a more aggressive PD target $(f T>$ MIC values of $51 \%$ ) considering that BSI is a life-threatening infection and potentially higher exposures would be needed. Further randomized clinical trials are needed to confirm ceftaroline role as a viable treatment option against $S$. aureus BSI. However, observational studies demonstrate ceftaroline viability as potential treatment option for this condition $[8,38]$. From the PD standpoint, even applying higher exposures targets ceftaroline performed well against the current $S$. aureus BSI isolates.

Teicoplanin has been widely reported as comparable to vancomycin in terms of efficacy and has been commonly prescribed in many parts of the world (excluding the USA) [44, 45]. Despite its availability in clinical practice for many years, the optimal PD profile is still under debate. Historically, trough concentrations have been utilized to characterize the adequacy of the glycopeptide PD profile; however, trough concentration alone is not an entirely appropriate target predictive of clinical success as sensitivity analysis demonstrated that even if a most aggressive trough concentration value was chosen (i.e., $>20 \mathrm{mg} /$ $\mathrm{L})$, the CFR observed in trough concentration targets was inferior to the PD value associated with successful outcome [34, 35, 46]. 


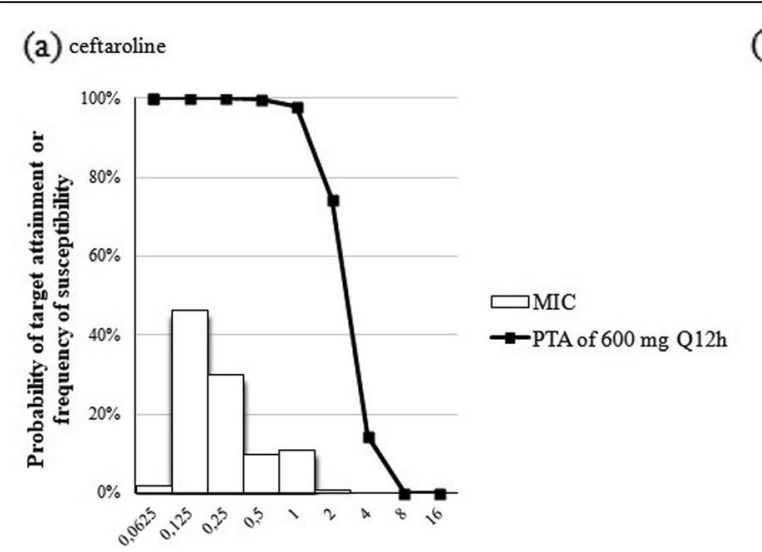

(b) daptomycin

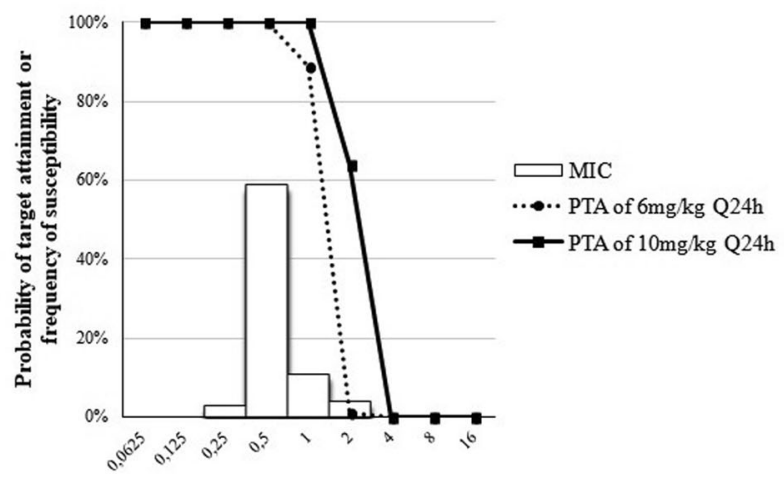

(c) linezolid 100

(d) linezolid 80
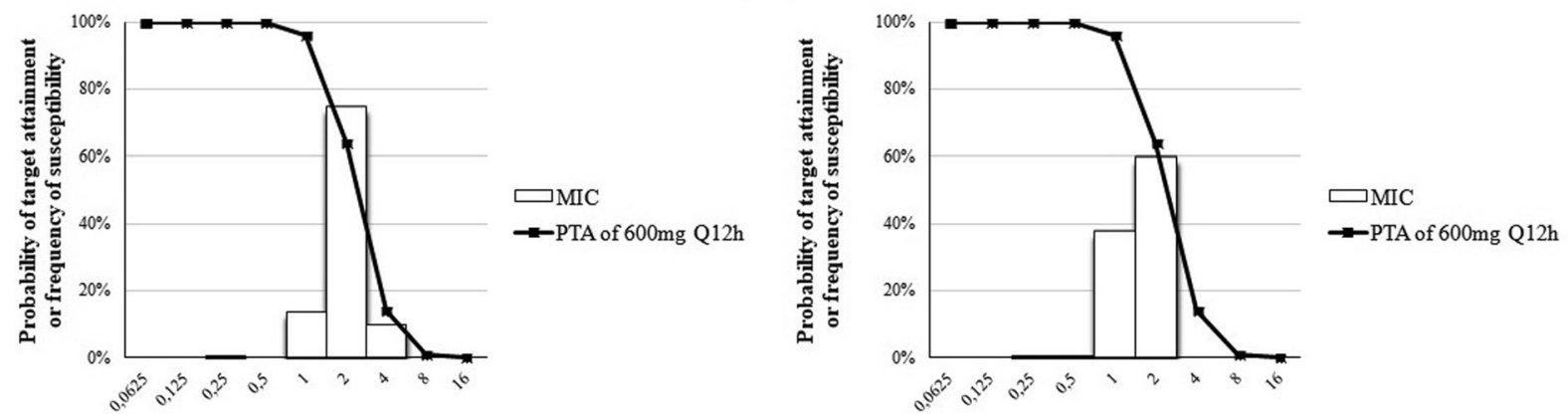

(e) teicoplanin

(f) vancomycin
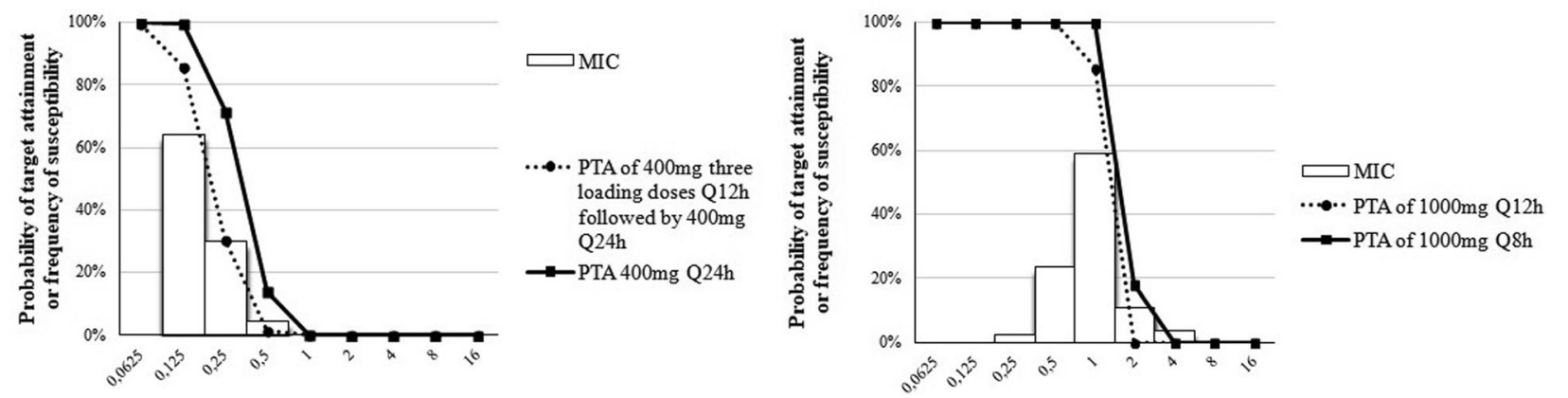

Fig. 1 Probability of target attainment as a function of increasing minimum inhibitory concentration (MIC)Lines represent PTA of each dose regimen. The MIC distributions in the plots show the frequency of isolates susceptibility. * The MIC values for linezolid were read at the first well where the trailing begins without regard for pinpoint trailing, as CLSI M100-S26 instructions, being designated as linezolid-80; and at 100\% inhibition of growth, being designated as linezolid-100. (a) Probability of ceftaroline achieving a fT MIC > 51\%; (b) Probability of daptomycin achieving a total AUC/MIC > 40; (c) and (d) Probability of linezolid 100 and linezolid 80 achieving a total AUC/MIC > 82.9; (e) Probability of teicoplanin achieving a total AUC/MIC > 900; (f) Probability of vancomycin achieving a total AUC/MIC > 350.

As a result of this discordance with trough value, we utilized a target AUC/MIC in the current study. Although a $400 \mathrm{mg}$ once-daily regimen of teicoplanin is often utilized in clinical practice, our data suggests that a $400 \mathrm{mg}$ q12h regimen will provide a more optimal PD profile. In agreement with our findings, a recent clinical study showed that teicoplanin maintenance dosing of $400 \mathrm{mg}$ q12h for severe infections due to MRSA provided higher clinical response rates and lower BSIrelated mortality rates [44].
In this study the linezolid regimen $(600 \mathrm{mg}$ q12h) presented a CFR of $77 \%$, far below the threshold defined as optimal response. This is partially explained by an elevated prevalence $(60 \%)$ of isolates with linezolid MIC $\geq 2 \mathrm{mg} / \mathrm{L}$. These findings were supported by the sensitivity analysis, given the large variation observed between the alternative PD targets proposed and even if less conservative PD target (reflecting the minimum PD index associated to clinical cure) were chosen, higher CFR thresholds were not achieved. Considering off-label use of linezolid for a 
Table 2 Cumulative fraction of responses (CFR) against 110 Staphylococcus aureus, including MRSA, from bloodstream infections

\begin{tabular}{llll}
\hline Antimicrobial & Regimen & $\begin{array}{l}\text { CFR } \\
\text { Sensitivity } \\
\text { Analysis }\end{array}$ \\
\hline Ceftaroline & $600 \mathrm{mg} \mathrm{q12h}$ & $98 \%$ & $96-99 \%$ \\
Daptomycin & $10 \mathrm{mg} / \mathrm{kg} \mathrm{q24h}$ & $92 \%$ & $21-100 \%$ \\
Teicoplanin & $400 \mathrm{mg}$ q12h & $86 \%$ & $44-78 \%$ \\
Daptomycin & $6 \mathrm{mg} / \mathrm{kg}$ q24h & $79 \%$ & $3-99 \%$ \\
Linezolid-80 & $600 \mathrm{mg}$ q12h & $77 \%$ & $51-94 \%$ \\
Vancomycin & $1000 \mathrm{mg}$ q8h & $76 \%$ & $71-77 \%$ \\
Teicoplanin & three $400 \mathrm{mg}$ loading doses q12h & $65 \%$ & $8-29 \%$ \\
& followed by $400 \mathrm{mg}$ q24h & & \\
Linezolid- & $600 \mathrm{mg}$ q12h & $64 \%$ & $34-87 \%$ \\
$100^{\mathrm{a}}$ & & & \\
Vancomycin & $1000 \mathrm{mg}$ q12h & $62 \%$ & $40-62 \%$ \\
\hline
\end{tabular}

${ }^{a}:$ MIC endpoint values for linezolid were read at the first well where the trailing begins without regard for pinpoint trailing, as CLSI M100-S26 instructions, being designated as linezolid-80; and at 100\% inhibition of growth, being designated as linezolid-100

potentially severe infection can be applied but other treatment options should be considered if isolates with linezolid MIC $\geq 2 \mathrm{mg} / \mathrm{L}$ are locally prevalent.

Only antimicrobials used for treatment of MRSA infections were accessed in the current study, although there are other available therapies not addressed in the current evaluation. Empirical therapy of S. aureus infections in hospital settings with elevated MRSA prevalence must consider a complex MIC distribution pattern and, consequently, complex drug exposure issues. A different scenario should be expected in environments with prevalent methicillin susceptible $S$. aureus.

Among the limitations of the present study, the selection of PK published studies included data derived from different clinical indications given the lack of comparable PK trials for each of these agents in the same patient population. On the other hand, we also avoided the inclusion of PK data derived exclusively from critically ill patients, due to the vast array of pathophysiological changes which affects antibiotic dosing in the critically ill [11]. Another potential limitation is that the results of any simulation are dependent on local MIC distributions and may vary among periods and institutions.

Finally, environments where $S$. aureus vancomycin MIC $\geq 2 \mu \mathrm{g} / \mathrm{mL}$ are prevalent may have concerns about vancomycin lack of activity, particularly for difficult to treat infections. Thus, stochastic methods can be used to guide antimicrobial stewardship in situations where several therapeutic options are currently available.

\section{Conclusions}

In conclusion, our study presents insights about alternative treatment strategies in setting where $S$. aureus vancomycin $\mathrm{MIC}$ is elevated (particularly $\geq 2 \mu \mathrm{g} / \mathrm{mL}$ ). In this scenario, ceftaroline and high dose daptomycin (10 $\mathrm{mg} / \mathrm{kg} \mathrm{q} 24 \mathrm{~h}$ ) regimens achieved CFRs $\geq 90 \%$, whilst teicoplanin high dose (400 mg q12 hours) regimen achieved better CFR when compared to the most effective vancomycin regimen, although below the defined optimal threshold.

\section{Abbreviations}

AUC: Area under the concentration time curve; BSI: Bloodstream infections; CFR: Cumulative fraction of response; CFU: Colony-forming unit; CLSI: Clinical \& laboratory standards institute; fAUC: Unbound drug fraction area under the concentration time curve; FDA: Food and drug administration; fT > MIC: Unbound drug fraction above minimum inhibitory concentrations; MIC: Minimum inhibitory concentrations; MRSA: Methicillin-resistant S. aureus; PD: Pharmacodynamic; PK: Pharmacokinetic; PTA: Probability of target attainment; VISA: Vancomycin intermediate S. aureus

\section{Acknowledgements}

We thank to AstraZeneca for the donation of ceftaroline powder. We also thank the Laboratory of Bacteriology of the University Hospital Clementino Fraga Filho (Adriana Lucia Pires Ferreira) for the granting of clinical isolates, Marlei Gomes da Silva for the technical support, Diego dos Santos Gonçalves for data visualization structure and Dr. Henry F. Chambers for the critics and review.

\section{Availability of data and material}

The data that support the findings of this study are available from the corresponding author, upon request.

\section{Authors' contributions}

TMC, GTC, PGMM: designed, collected, executed, performed the analysis, wrote the report; SAN, KRNS, DPN, CRVK: supervised the analysis, critically reviewed the experiment, data interpretation and discussed the results. All authors read and approved the final manuscript.

\section{Authors' information}

TMC, PGMM, KRNS: Laboratório de Infecção Hospitalar, Departamento de Microbiologia Médica, Instituto de Microbiologia Paulo de Góes, Universidade Federal do Rio de Janeiro, Rio de Janeiro, RJ, Brazil; GTC, CRVK: Laboratório Especial de Microbiologia Clínica, Disciplina de Infectologia, Escola Paulista de Medicina, Universidade Federal de São Paulo (UNIFESP), São Paulo, SP, Brazil. SAN: Hospital Universitário Clementino Fraga Filho, Faculdade de Medicina, Universidade Federal do Rio de Janeiro, Rio de Janeiro, RJ, Brazil. DPM: Center for Anti-infective Research and Development, Hartford Hospital, 80 Seymour Street, Hartford, CT.

\section{Funding}

This work was supported by Fundação Carlos Chagas Filho de Amparo à Pesquisa do Estado do Rio de Janeiro (FAPERJ); Conselho Nacional de Desenvolvimento Científico e Tecnológico (CNPq); Coordenação de Aperfeiçoamento de Pessoal de Nível Superior (CAPES); Fundação Universitária José Bonifácio (FUJB) and Programa de Apoio aos Núcleos de Excelência (PRONEX). The funding body did not have no role in the design of the study and collection, analysis, interpretation of data and in writing the manuscript.

Ethics approval and consent to participate

The study was approved by the Ethics Committee of the Human Research Ethics Committee of the University Hospital Clementino Fraga Filho (number 008/15) and no Informed Consent was required, since data were exclusively grouped and analyzed under confidential and anonymous circumstances. Only researchers had access to individual data, which are not characterized nor disclosed under any circumstances. Data used in this study was anonymized before its use. 


\section{Competing interests}

The authors declare that they have no conflict of interest.

\begin{abstract}
Author details
'Laboratório de Infecção Hospitalar, Departamento de Microbiologia Médica, Instituto de Microbiologia Paulo de Góes, Universidade Federal do Rio de Janeiro, Av. Carlos Chagas Filho, 373 - bloco I, Sala 12-010, Cidade Universitária Rio de Janeiro, Rio de Janeiro, Brazil. ${ }^{2}$ Laboratório Especial de Microbiologia Clínica, Disciplina de Infectologia, Escola Paulista de Medicina Universidade Federal de São Paulo (UNIFESP), Rua Leandro Dupret, São Paulo, SP 188, Brazil. ${ }^{3}$ Center for Anti-infective Research and Development, Hartford Hospital, 80 Seymour Street, Hartford, CT, USA. ${ }^{4}$ Hospital Universitário Clementino Fraga FilhoFaculdade de Medicina, Universidade Federal do Rio de Janeiro, Rua Rodolpho Paulo Rocco, 255, Rio de Janeiro, RJ, Brazil.
\end{abstract}

Received: 30 April 2019 Accepted: 9 January 2020

Published online: 23 January 2020

\section{References}

1. Allegranzi B, Bagheri Nejad S, Combescure C, Graafmans W, Attar H, Donaldson $\mathrm{L}$, et al. Burden of endemic health-care-associated infection in developing countries: systematic review and meta-analysis. Lancet. 2011; 377:228-41.

2. Marra AR, Camargo LFA, Pignatari ACC, Sukiennik T, Behar PRP, Medeiros EAS, et al. Nosocomial bloodstream infections in Brazilian hospitals: analysis of 2,563 cases from a prospective Nationwide surveillance study. J Clin Microbiol [Internet] 2011;49:1866-1871. Available from: http://jcm.asm.org/ cgi/doi/https://doi.org/10.1128/JCM.00376-11

3. Sievert DM, Ricks P, Edwards JR, Schneider A, Patel J, Srinivasan A, et al. Antimicrobial-resistant pathogens associated with healthcare-associated infections summary of data reported to the National Healthcare Safety Network at the Centers for Disease Control and Prevention, 2009-2010. Infect Control Hosp Epidemiol. 2013;34:1-14.

4. Rodvold KA, McConeghy KW. Methicillin-resistant Staphylococcus aureus therapy: past, present, and future. Clin Infect Dis. 2014;58:S20-7.

5. Gomes DM, Ward KE, LaPlante KL. Clinical implications of Vancomycin Heteroresistant and intermediately susceptible Staphylococcus aureus. Pharmacotherapy. 2015;35:424-32.

6. Van Hal SJ, Lodise TP, Paterson DL. The clinical significance of vancomycin minimum inhibitory concentration in Staphylococcus aureus infections: A systematic review and meta-analysis. Clin. Infect. Dis. 2012:755-71.

7. Li J, Zhao Q-H, Huang K-C, Li Z-Q, Zhang L-Y, Qin D-Y, et al. Linezolid vs. vancomycin in treatment of methicillin-resistant staphylococcus aureus infections: a meta-analysis. Eur rev med Pharmacol Sci [internet]. 2017;21: 3974-9 Available from: http://www.ncbi.nlm.nih.gov/pubmed/28975963.

8. Arshad S, Huang V, Hartman P, Perri MB, Moreno D, Zervos MJ. Ceftaroline fosamil monotherapy for methicillin-resistant Staphylococcus aureus bacteremia: a comparative clinical outcomes study. Int J Infect Dis [Internet]. Int Soc Infect Dis; 2017;57:27-31. Available from: http://dx.doi.org/https:// doi.org/10.1016/j.jijid.2017.01.019

9. Fowler V, Saglio G, Wook Kim D, Issaragrisil S, le Courtre P, Etienne G, et al. Daptomycin versus standard therapy for bacteremia and endocarditis caused by Staphylococcus aureus. N Engl J Med. 2006;362:2251-9.

10. Bradley JS, Dudley MN, Drusano GL. Predicting efficacy of antiinfectives with pharmacodynamics and Monte Carlo simulation. Pediatr. Infect. Dis. J. 2003: 982-93.

11. Roberts JA, Kirkpatrick CMJ, Lipman J. Monte Carlo simulations: maximizing antibiotic pharmacokinetic data to optimize clinical practice for critically ill patients. J Antimicrob Chemother. 2011;66:227-31.

12. Nielsen El, Friberg LE. Pharmacokinetic-pharmacodynamic modeling of antibacterial drugs. Pharmacol Rev [Internet]. 65:1053-2013, 1090 Available from: http://www.ncbi.nlm.nih.gov/pubmed/23803529.

13. Kuti JL, Kiffer CRV, Mendes CMF, Nicolau DP. Pharmacodynamic comparison of linezolid, teicoplanin and vancomycin against clinical isolates of Staphylococcus aureus and coagulase-negative staphylococci collected from hospitals in Brazil. Clin Microbiol Infect [Internet]. 2008;14:116-23 Available from: http://www.ncbi.nlm.nih.gov/pubmed/18076672.

14. Housman ST, Sutherland CA, Nicolau DP. Pharmacodynamic profile of commonly utilised parenteral therapies against meticillin-susceptible and meticillin-resistant Staphylococcus aureus collected from US hospitals. Int J Antimicrob Agents. 2014;44:235-41.

15. da Costa TM, Morgado PGM, Cavalcante FS, Damasco AP, Nouér SA, dos Santos KRN. Clinical and Microbiological Characteristics of Heteroresistant and Vancomycin-Intermediate Staphylococcus aureus from Bloodstream Infections in a Brazilian Teaching Hospital. de Lencastre H, editor. PLoS One [Internet]. 2016;11:e0160506. Available from: http://dx.plos.org/https://doi. org/10.1371/journal.pone.0160506

16. Bannerman TPS. Staphylococcus, Micrococcus, and other catalase-positive cocci. Murray PR, Baron EJ, Jorgensen JH, Landry MJ, Pfaller MA Ed Man Clin Microbiol Washingt. 2007;390-410.

17. CLSI. Performance standards for antimicrobial susceptibility testing. 27th ed. CLSI supplement M100. Wayne, PA: Clinical and Laboratory Standards Institute. Perform. Stand. Antimicrob. susceptibility testing. 27th ed. CLSI Suppl. M100. Wayne, PA Clin. Lab. Stand. Inst. 2017.

18. Milheirico C, Oliveira DC, de Lencastre H. Update to the multiplex PCR strategy for assignment of mec element types in Staphylococcus aureus. Antimicrob Agents Chemother [Internet]. 2007;51:3374-3377. Available from: http://aac.asm.org/cgi/doi/https://doi.org/10.1128/AAC.00275-07

19. Di Paolo A, Tascini C, Polillo M, Gemignani G, Nielsen El, Bocci G, et al. Population pharmacokinetics of daptomycin in patients affected by severe Gram-positive infections. Int J Antimicrob Agents [Internet]. Elsevier B.V.; 2013;42:250-255. Available from: http://dx.doi.org/https://doi.org/10.1016/j. ijantimicag.2013.06.006

20. Meagher AK, Forrest A, Rayner CR, Birmingham MC, Schentag JJ. Population pharmacokinetics of linezolid in patients treated in a compassionate-use program. Antimicrob Agents Chemother. 2003;47:548-53.

21. Lortholary O, Tod M, Rizzo N, Padoin C, Biard O, Casassus P, et al. Population pharmacokinetic study of teicoplanin in severely neutropenic patients. Antimicrob agents Chemother [Internet]. 1996;40:1242-7 Available from: http://www.ncbi.nlm.nih.gov/pubmed/8723474.

22. Moise-Broder PA, Forrest A, Birmingham MC, Schentag JJ. Pharmacodynamics of vancomycin and other antimicrobials in patients with Staphylococcus aureus lower respiratory tract infections. Clin Pharmacokinet. 2004;43:925-42.

23. Dandekar PK, Tessier PR, Williams P, Nightingale $\mathrm{CH}$, Nicolau DP. Pharmacodynamic profile of daptomycin against Enterococcus species and methicillin-resistant Staphylococcus aureus in a murine thigh infection model. J Antimicrob Chemother [Internet]. 2003;52:405-411. Available from: https:// academic.oup.com/jac/article-lookup/doi/https://doi.org/10.1093/jac/dkg337

24. Andes D, Van Ogtrop ML, Peng J, Craig WA. In vivo pharmacodynamics of a new oxazolidinone (linezolid). Antimicrob Agents Chemother. 2002;46:3484-9.

25. Takeda Y, Matsumoto K, Watanabe E, Kanazawa N, Fukamizu T, Shigemi A, et al. Pharmacokinetic/pharmacodynamic analysis of teicoplanin in patients with MRSA infections. Clin Pharmacol Adv Appl [Internet]. 2016;15 Available from: https://www.dovepress.com/pharmacokineticpharmacodynamicanalysis-of-teicoplanin-in-patients-wit-peer-reviewed-article-CPAA.

26. Van Wart SA, Ambrose PG, Rubino CM, Khariton T, Riccobene TA, Friedland $H D$, et al. Pharmacokinetic-pharmacodynamic target attainment analyses to evaluate in vitro susceptibility test interpretive criteria for ceftaroline against Staphylococcus aureus and Streptococcus pneumoniae. Antimicrob Agents Chemother. 2014;58:885-91.

27. Benvenuto M, Benziger DP, Yankelev S, Vigliani G. Pharmacokinetics and tolerability of daptomycin at doses up to 12 milligrams per kilogram of body weight once daily in healthy volunteers. Antimicrob Agents Chemother. 2006;50:3245-9.

28. MacGowan AP. Pharmacokinetic and pharmacodynamic profile of linezolid in healthy volunteers and patients with Gram-positive infections. J Antimicrob Chemother [Internet]. 2003;51:17ii - 1725. Available from: https://academic. oup.com/jac/article-lookup/doi/https://doi.org/10.1093/jac/dkg248

29. Moise PA, Forrest A, Bhavnani SM, Birmingham MC, Schentag JJ. Area under the inhibitory curve and a pneumonia scoring system for predicting outcomes of vancomycin therapy for respiratory infections by Staphylococcus aureus. Am J Heal Pharm. 2000;57.

30. Bhavnani SM, Hammel JP, Van Wart SA, Rubino CM, Reynolds DK, Forrest A, et al. Pharmacokinetic-Pharmacodynamic analysis for efficacy of Ceftaroline Fosamil in patients with acute bacterial skin and skin structure infections. Antimicrob Agents Chemother [Internet] 2015;59:372-380. Available from: http://aac.asm.org/lookup/doi/https://doi.org/10.1128/AAC.02531-14

31. Van Wart SA, Forrest A, Khariton T, Rubino CM, Bhavnani SM, Reynolds DK, et al. Population pharmacokinetics of ceftaroline in patients with acute 
bacterial skin and skin structure infections or community-acquired bacterial pneumonia. J Clin Pharmacol. 2013:53:1155-67.

32. Mouton JW, Dudley MN, Cars O, Derendorf H, Drusano GL. Standardization of pharmacokinetic/pharmacodynamic (PK/PD) terminology for antiinfective drugs: an update. J Antimicrob Chemother [Internet]. 2005 [cited 2011 Jul 13];55:601-607. Available from: http://www.ncbi.nlm.nih.gov/ pubmed/15772142.

33. Rayner CR, Forrest A, Meagher AK, Birmingham MC, Schentag JJ. Clinical pharmacodynamics of linezolid in seriously ill patients treated in a compassionate use Programme. Clin Pharmacokinet. 2003;42:1411-23.

34. Byrne CJ, Egan S, Fennell JP, Byrne PO, Enright H, Deasy E, et al. Teicoplanin use in adult patients with haematological malignancy: Exploring relationships between dose, trough concentrations, efficacy and nephrotoxicity. Int J Antimicrob Agents [Internet]. Elsevier B.V:; 2015;1-7. Available from: http://dx. doi.org/https:/doi.org/10.1016/.ijantimicag.2015.05.019

35. Matsumoto K, Kanazawa N, Fukamizu T, Shigemi A, Yaji K, Shimodozono Y, et al. Determination of teicoplanin trough concentration target and appropriate total dose during the first 3 days: a retrospective study in patients with MRSA infections. J Infect Chemother [Internet]. 2010;16:193-9 Available from: http://linkinghub.elsevier.com/retrieve/pii/S1341321X10706012.

36. Gasch O, Camoez M, Domínguez MA, Padilla B, Pintado V, Almirante B, et al. Predictive factors for early mortality among patients with methicillinresistant staphylococcus aureus bacteraemia. J Antimicrob Chemother. 2013;68:1423-30.

37. Holmes N, Tong S, Davis J, Hal S. Treatment of methicillin-resistant Staphylococcus aureus: Vancomycin and beyond. Semin Respir Crit Care Med [Internet] 2015;36:017-030. Available from: http://www.thieme-connect. de/DOI/DOI?https://doi.org/10.1055/s-0034-1397040

38. Zasowski EJ, Trinh TD, Claeys KC, Casapao AM, Sabagha N, Lagnf AM, et al. Multicenter observational study of ceftaroline fosamil for methicillinresistant Staphylococcus aureus bloodstream infections. Antimicrob Agents Chemother [lnternet]. 2017;61:AAC.02015-AAC.02016. Available from: http:// aac.asm.org/lookup/doi/https://doi.org/10.1128/AAC.02015-16

39. Gould IM, Miró JM, Rybak MJ. Daptomycin: The role of high-dose and combination therapy for Gram-positive infections. Int J Antimicrob Agents [Internet]. Elsevier B.V.; 2013;42:202-210. Available from: http://dx.doi.org/ https://doi.org/10.1016/j.jijantimicag.2013.05.005

40. Kullar R, Sakoulas G, Deresinski S, Van Hal SJ. When sepsis persists: A review of MRSA bacteraemia salvage therapy. J. Antimicrob. Chemother. 2016:576-86.

41. Cui L, Tominaga E, Neoh HM, Hiramatsu K. Correlation between reduced daptomycin susceptibility and vancomycin resistance in vancomycinintermediate Staphylococcus aureus. Antimicrob Agents Chemother. 2006; 50:1079-82.

42. Pankey GA, Sabath LD. Clinical relevance of bacteriostatic versus bactericidal mechanisms of action in the treatment of gram-positive bacterial infections. Clin Infect Dis [Internet] 2004;38:864-870. Available from: https://academic. oup.com/cid/article-lookup/doi/https://doi.org/10.1086/381972

43. Werth BJ, Barber KE, Ireland CE, Rybak MJ. Evaluation of ceftaroline, vancomycin, daptomycin, or ceftaroline plus daptomycin against daptomycin-nonsusceptible methicillin-resistant staphylococcus aureus in an in vitro pharmacokinetic/pharmacodynamic model of simulated endocardial vegetations. Antimicrob Agents Chemother. 2014;58:3177-81.

44. Lee C, Tsai C-Y, Li C-C, Chien C-C, Liu J-W. Teicoplanin therapy for MRSA bacteraemia: a retrospective study emphasizing the importance of maintenance dosing in improving clinical outcomes. J Antimicrob Chemother [Internet]. 2015;70:257-263. Available from: https:/academic. oup.com/jac/article-lookup/doi/https://doi.org/10.1093/jac/dku335.

45. Yoon YK, Park DW, Sohn JW, Kim HY, Kim YS, Lee CS, et al. Multicenter prospective observational study of the comparative efficacy and safety of vancomycin versus teicoplanin in patients with health care-associated methicillin-resistant staphylococcus aureus bacteremia. Antimicrob Agents Chemother. 2014;58:317-24.

46. Pea F, Brollo L, Viale P, Pavan F, Furlanut M. Teicoplanin therapeutic drug monitoring in critically ill patients: a retrospective study emphasizing the importance of a loading dose. J Antimicrob Chemother [Internet] 2003;51: 971-975. Available from: https://academic.oup.com/jac/article-lookup/doi/ https://doi.org/10.1093/jac/dkg147.

\section{Publisher's Note}

Springer Nature remains neutral with regard to jurisdictional claims in published maps and institutional affiliations.

Ready to submit your research? Choose BMC and benefit from:

- fast, convenient online submission

- thorough peer review by experienced researchers in your field

- rapid publication on acceptance

- support for research data, including large and complex data types

- gold Open Access which fosters wider collaboration and increased citations

- maximum visibility for your research: over $100 \mathrm{M}$ website views per year

At BMC, research is always in progress.

Learn more biomedcentral.com/submissions 